\title{
Studying Quality Factors of Townscape in Coasts Case Study: Joffre Neighborhood Center in Persian Gulf Coast of Boushehr
}

\author{
Rahil Nadoomi ${ }^{1}$, Zahra Shamsi ${ }^{2} \&$ Maryam NikbakhtDehkordi ${ }^{3}$ \\ ${ }^{1}$ Master of Architecture, Daneshpajoohan Institute, Isfahan, Iran \\ ${ }^{2}$ Master of Architecture, Azad University, Boushehr, Iran \\ ${ }^{3}$ Master of Architecture, Daneshpajoohan Institute, Isfahan, Iran \\ Correspondence: Rahil Nadoomi, Master of Architecture, No. 2, Baharestan 18, Ashoori St., Boushehr, Iran. \\ Tel: 9891-7668-5545. E-mail: rahilnadoomi@gmail.com
}

Received: May 27, 2016

doi:10.5539/mas.v10n11p90
Accepted: June 24, 2016

Online Published: July 29, 2016

URL: http://dx.doi.org/10.5539/mas.v10n11p90

\begin{abstract}
Men's tendency and requirement have been increased for being represented in natural areas in the city through industrialization and cities development. On the one hand, the necessity of surviving of urban damaged and dense areas and protecting and improvement of natural resources in cities and on the other hand, the townscape has been considered because of increasing the quality of urban spaces of environment in nature. Based on these views, surviving sea coasts, wharfs, green spaces, making connection among them and urban residential areas require coordination between environmental approaches and urban issues and solutions should be chosen to provide a balance among urban, aesthetic and ecology approaches. The present essay attempts to study the concept of townscape quality through descriptive-analysis method by considering Joffre coastal neighborhood center in western south of Boushehr as a part of coastal townscape and effective indicators on its quality and present solutions for promoting and improving the quality of coastal townscape in the studied part.
\end{abstract}

Keywords: townscape, coast, boushehr, Joffre neighborhood center

\section{Introduction}

The landscape of a city is a collection of natural and artificial factors that is formed through affection of natural, cultural, social, economic special features of that especial city and it is a place that special features change to reality. The townscape is an objective and real item as an introduced category in cities' quality and desirability and it is achieved through observing and understanding different and tangible manifestations of the city such as buildings, spaces, activities, voices, smells at the time of citizens' encountering with the city phenomena (in different scales including seeing the city from far distance or when they are located in city or even in buildings). The economic and social relations in cities have been led to emersion of new manifestations of townscape that sometimes are different from background culture and social origin of the region. Also, the coastal neighborhood center of Joffre in Boushehr is not exception. This neighborhood center which is located at the vicinity of Persian Gulf coast has been encountered with intensive physical and functional changes such as disruption of space structure, physical destruction of buildings and sometimes, complete destroying of spaces with native and un-static materials, disturbance in movement system between the neighborhood center and sea, the existence of incompatible usages in coastal line, the lack of collective-social service spaces in recent decades because of constructions without considering the neighborhood center location and structure and its citizens' profession.

\section{Theoretical Basis}

\subsection{Quality}

"Quality" is a word which has been understood in all art, scientific and industrial subjects intuitively and used in the framework of disputation in related areas continuously. This word is a two-faced concept; it is a clear and explicit and also multilateral concept. When it is used for tangible qualities such as hardness, softness, speed and etc., it has a clear and understandable concept, but when it is used for intangible qualities such as beauty, magnificence, effectiveness and etc. it will be changed to an evasive and multilateral concept. The extent of dimensions and sides of two mentioned states changes the concept of "quality" to a relative concept which has 
an extra and different meaning from its usual and obvious one (Golkar, 2000, p. 38).

Billings has explained the "quality" of a thing in this way: a collection of distinct features or characteristics that causes the differentiation of a thing from others and it makes us capable to judge about priority, similarity or inferiority of something in comparison with another thing. And aesthetically, we can judge about its beauty and obscenity, badness or goodness and practically about being better or worse and effective or non-effective (Billings, 1993, p. 2)

\subsection{Townscape}

The landscape is the result of human's interaction and environment in outside spaces. Studying the landscape or different dimensions of its perceptions is possible from methods of studying the city and urban regions. The expression of townscape has been used by Gordon Cullen in his book "Townscape" for the first time. Through his emphasis on emotional affects that the townscape can have on urban citizens and visitors, he has demanded visual pleasure in the scale city. Cullen's main discussion has been about this fact that buildings will make a visual desirability that none of them cannot create it alone (Cullen, 2003, p. 10).

Based on Rapoport's interpretation, townscape is a generality from interaction between human (observer) and his environment that will remain in his mind even after leaving the place. The townscape is a collection of gestalts. It becomes a subjective generality when it is given a stable meaning which is derived from its cultural or regional capacity. Actually, the townscape is a connected generality from symbols and signs that gives the reality to values, meanings and similar things (Golkar, 2006, p. 40).

Edmond Bacon in a part of his book "Designs of Cities" has studied the problem of knowledge about space as an experience by mentioning the communion of internal-space elements and considered the items which are recognizable in townscape obviously such as seeing the sky and earth, points and surfaces, depth, ups and downs their relation with human which are models that are effective in explaining space (Bacon, 1976, pp. 15-27).

Also, Lynch has studied the mentioned issue based on subjective point of view and considered five main factors of city view: path, edge, node, landmarks and distinct in formation of city view in people's mind (Lynch, 2006, p. 90). Gordon Cullen has expressed results about his studies in relation to townscape in four scopes: successive view, place, content and functional tradition. Therefore, different concepts such as territory, turning point, inside landscape, marking, changing surface, complexity, precision, and many other concepts have been studied too (Cullen, 2003, p. 6).

Generally, systematized and desirable townscape has created pleasure feeling of living in urban environment and has been one of main factors in relation to the city and citizens. When the townscape is encountered with disarrangement, confusion and non-identity, these feelings have also transferred to citizens and appeared as urban abnormal behaviors and on the other hand, they destroy the logical relation between them and the city.

\subsection{The Existential Condition of Townscape Quality}

The problem of existential condition in relation to quality is derived from two arenas "individual's subjective arena" and "thing's objective arena". The qualities belonged to subjective arena is located in individual's ego. Mutually, the qualities belonged to objective arena are located as an outside existence subject to mind and deals with the realities of outside world. Golkar (2000, p. 43) expresses the existed ideas in relation to existential condition of townscape based on two arenas as followed:

1. Treating the townscape as a quality or feature that originally belongs to physical environment of the city and is existed from human as an observer and evidence independently.

2. Treating the townscape as a complete subjective and personalization category which has been made by observer and it does not have any relation with physical structure and characteristics of environment.

3. Treating the townscape as a phenomena and an event which is formed during the exchange between physical and tangible features of the environment from one hand and models and cultural codes and observer's mental abilities on the other hand.

\subsection{The Quality of Coastal Townscape}

Wherever water has manifested in the city, always, it has played an obvious role in attracting people of that city or passengers. Usually, this manifestation has been like a river that crosses among the city or a sea, a lake or a gulf which has been widespread near the city. Each of these cases has a significant role in the feature of many important cities in the world, so that the waterfront has played a key role in citizens or passengers ' mental picture of that city as an indicator element. Also, the waterfront can be a bed for many events on urban scale and local scale. The elements such as bridges and wharf which have been created in relation to these waterfronts and 
their near water also have the same potential (Pakzad, 2010, p. 353).

In coastal cities or cities where a river flows in them, the coast is a memorable and historical area of the city that usually, the core and historical center of the city are located beside them (Mansouri, 2010, p. 4). Actually, the coast and coastal stripe of the city has a key role in explaining the townscape and it is considered as a valuable source for promoting environmental qualities. The quality of townscape has been studied based on different point of views that in continue four of them are discussed as followed:

\subsubsection{The Physical Quality of Coastal Townscape}

The physical structure of coastal townscape should be in the event of satisfying human's requirements and for improving and evolution of public areas of the city. The physical qualities of townscape are in relation with access method, location and physiological welfare in different climate and safety (Kaplan \& Kaplan, 1998, p. 14). The made usages around the coast and the method of their development, being responsive of usages to citizens' requirements, organizing open spaces and their distributing and dispensation in the coast have affected the physical quality of coast townscape significantly. One of the main principals of townscape is considering banks including: banks with existed value, banks required improvement and suggested banks. Based on environmental quality according to landscape and the method of its exploitation, the important points for physical structure in coastal townscape are incorporation of homogenous and familiar forms in the coast and creating the spaces which have the potential for creating memorability.

\subsubsection{The Cultural and Social Quality of Coastal Townscape}

Landscapes are inevitable results of cultural interpretations and representations of the culture during the time. Expressing the landscape in relation to culture is the result of human's existence in the environment. The urban natural environments and the form of the city have created together the history of interaction between natural process and human's actions during the time (Spirn, 1984, p. 162). The townscape has a significant role in sharing people in social activities, considering cultural requirements and protecting native identity of the region. Therefore, the correct understanding of consumers' requirements from space, kinds of interests and their points of views give a new opportunity for achieving proper ideas. Through this point of view, a desirable coastal landscape has spaces which give the possibilities of partnership, exchange of views and creating memorability to human's group and lead to record common memories and belonging to these spaces. The cultural structure of coastal landscape includes perceptional and behavioral dimensions that can be considered as a gift from social-cultural structure of the city.

\subsubsection{The Aesthetical Quality of Coastal Townscape}

Needing beauty is a part of human's most unknown requirement. Malraux believes that this requirement is existed in some people. These people become sick by seeing obscenity and they will be cured by being in beautiful environments. The effect of this tendency is obvious in different aspects such as environment organizing, townscape, and resolving some of people's material and spiritual requirements. According to architectural beauty, the environment and landscape are inevitable; because the content of a work is usually transformed to a frame of a physical form (Feyzi, 2007, p. 124).

Each beauty has a value and it should be considered that the purpose of value in visual beauty is protecting and keeping people's cultural and social values of that city which they reveal themselves in a logical and principled composition in the view of city (Bell, 2003, p. 36). Generally, the purpose of planning landscape leads to creating beautiful spaces and decreasing undesirable visual environments in urban environments. Therefore, for planning the landscape in the coastal environments, it needs a deep consideration to protecting the natural beauty of the coast and creating lateral spaces and satisfying people's requirements. Concentrating on visual information in the environment as a communication language can express a discussion between the designer and audiences (Feyzi, 2007, p. 125).

\subsubsection{The Ecological Quality of Coastal Townscape}

The landscape architecture has been introduced from the beginning of the history in interchange with other activities in relation to decorating earth. Experimentally, human has attempted to control his biological environment based on physical, physiological, psychological, security and social requirements and etc. through reacting against natural dominant forces in different ages to safe himself from probable adversities and live in welfare (Esfandiyari, 1997, p. 64). Human's requirements have not been coincidence with natural ecosystem and neglecting the existed nature can insert irreparable damages to existed resources in the earth. In this relation, there is a close connection between landscape ecology and human's ecology. Therefore, the view of different societies has not actually been changed for exploiting from these resources, as development models consist of 
least damages and extreme protection of the environment. Based on these conditions, natural and environmental resources can be protected and offered to future generation. The necessity of considering the environment and also its protecting in the process of landscape designing and planning is an important fact. In ecology of the landscape, instead of studying environments separately, existed structures and models in landscape are analyzed and designed (Feyzi, 2007, p. 128).

\section{The Coastal Townscape of Boushehr, Persian Gulf Coast; Joffre Neighborhood Center}

\subsection{The Location of Joffre Neighborhood Center}

Joffre is located in western south of Boushehr and it is closed from east to Chamran Street and west to Persian Gulf Street. Its entire western boundary is toward the coast and Joffre fishing pond is connected to it. Also, some important buildings of the city such as municipality building are built in this region. Being at the vicinity of western coast and also location of fishing ponds has made this region different. The landscapes toward sea and the frequency of berthed boats and dhows in the coast in addition to fishing activities are the principal identity of this region.

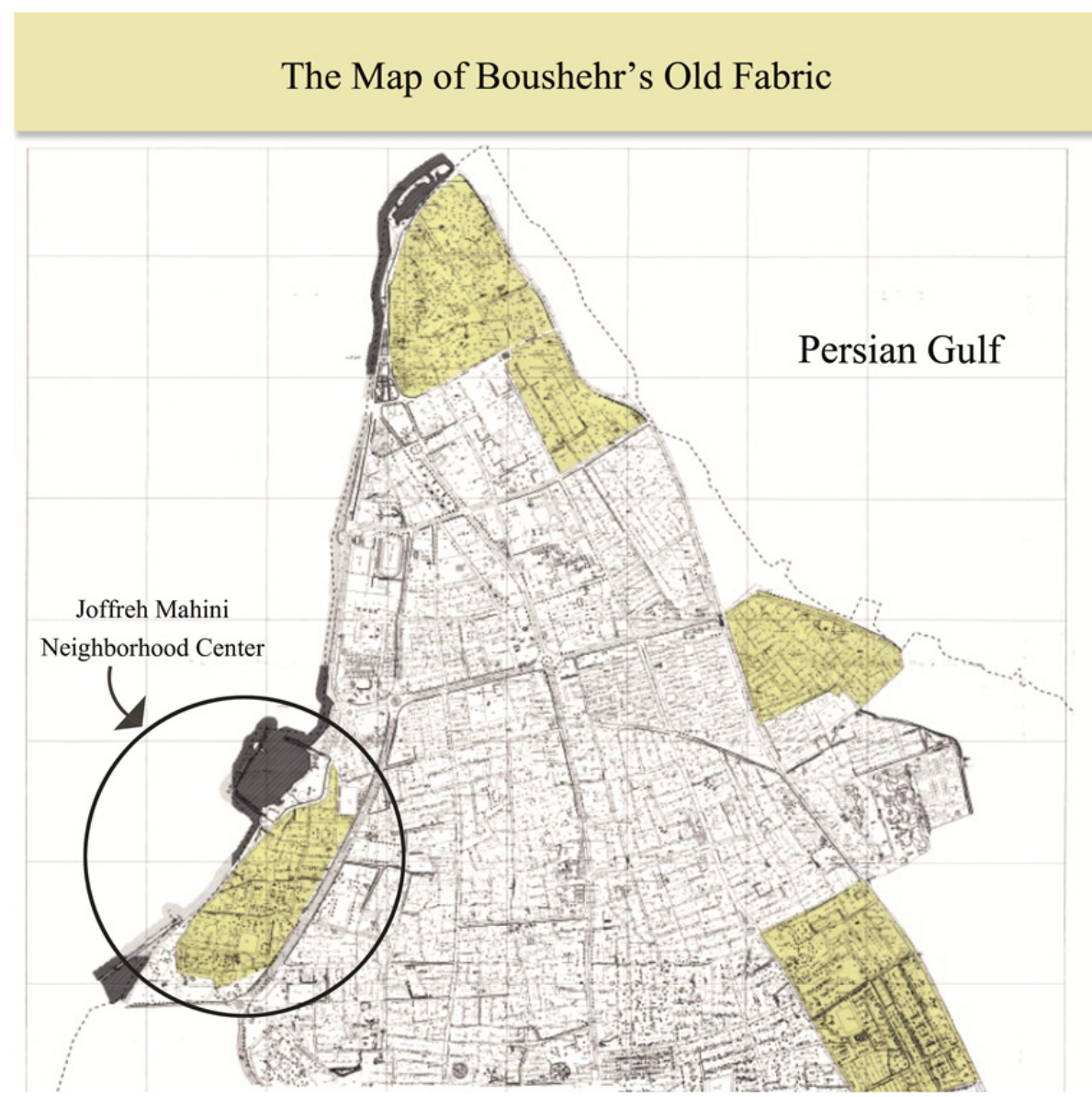

Figure 1. The location of Joffre neighborhood center in the city (Detailed Plan of Boushehr, 2006)

\subsection{Studying Effective Factors in the Landscape of Joffre}

As researchers and architects have presented different explanations about landscape, also they have different point of views in relation to effective factors in townscapes. The features such as usage, movement and access, the physical form of the city and environment are common among almost architects. In continue, these factors are studied generally and strengths, weaknesses, opportunities and every threat that they are encountered in Joffre neighborhood center are analyzed in a table.

- Usage: the most important feature of usage in this region is being in the vicinity of Joffre wharf, municipality building, stadium and military areas. On the other hand, sport fields give an especial importance to 
this region extremely. The most important usages in Joffre neighborhood center in urban scale are municipality building and Stadium.

- Movement and Access: this region is connected to access network from two ways. From west to coast street of Persian Gulf and from east to Chamran wide street. Permeability of this region based on very wide vehicle roads is very high for passengers and drivers.

- The Physical Form of the City: the structure model is different in various blocks and it includes from residential sky scraper building to $40 \%$ and $60 \%$ buildings. Rebuilding is applied in this region and many building are in the process of constructing. Also, extremely old buildings are seen in this region.

Joffre is explained and bounded by important elements of urban space organization. From west it is reached to the western coast and the street is closed along it and from west to Chamran Street. In another side, three main nodes of the city, Daliran Tangestan Square, Raeesali Delvari Square and Military Force Martyrs Square have made its corners. Joffre fishing pond is in its neighborhood and Boushehr municipality building is located in the big possession part in the north of this region.

- Environment: this region is encountered with intensive pollution of urban spaces such as municipal waste, sewage, surface water, construction waste of destructed buildings and accumulated in arid lands and other new materials like other Bushehr neighborhood centers that each of them has harmful environmental effects. Also, the consuming of electricity energy is high because of the frequency of the gas air conditions which have been increased by changing in the model of building construction like the rest of the city. The vegetation is seen as low-number rows of the trees and arboriculture is seldom seen in house yards. Public health and cleaning are low. The problems of Joffre fishing wharf impose its environmental effects on this region.

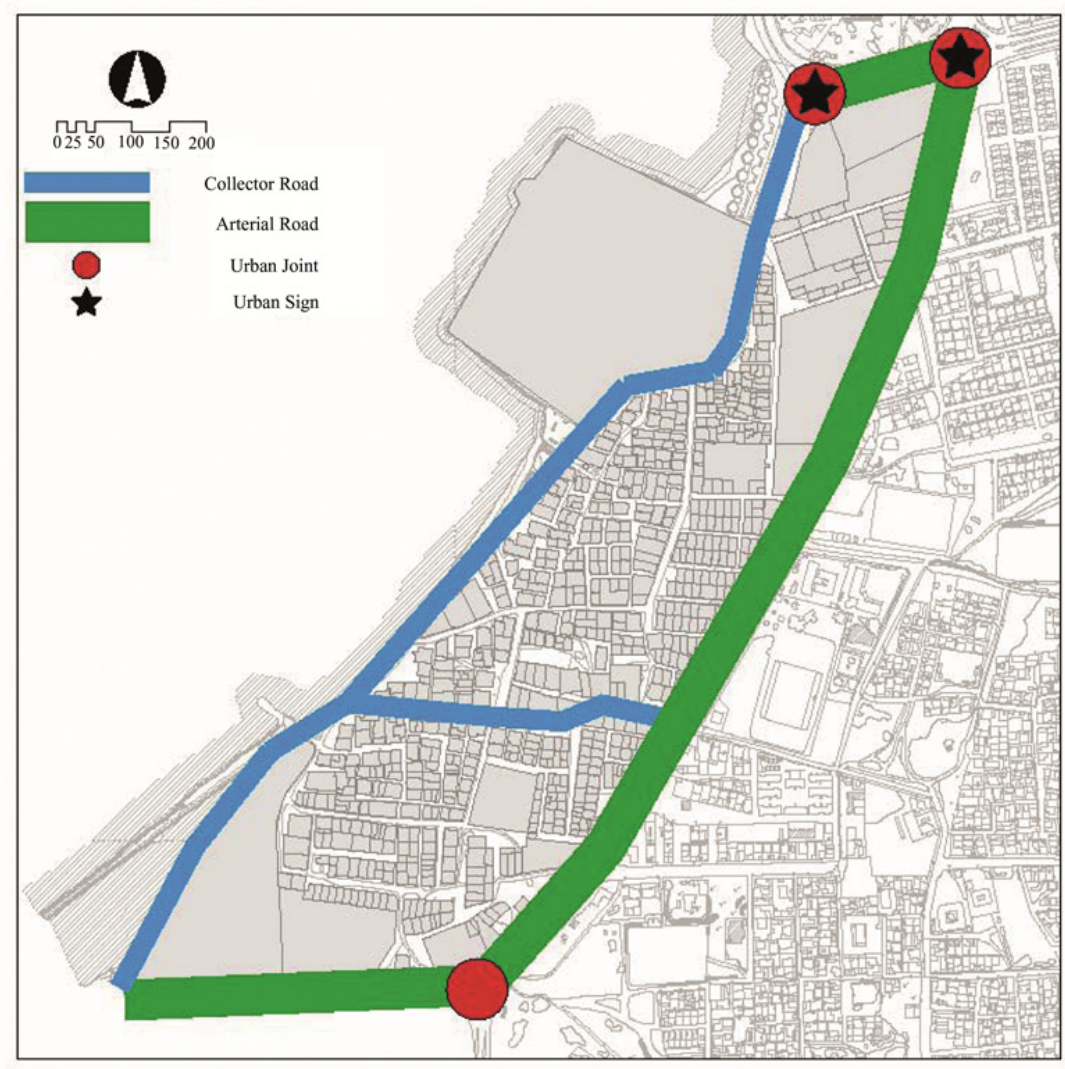

Figure 2. The plan of Joffre accesses (Detailed Plan of Boshrhr, 2006) 


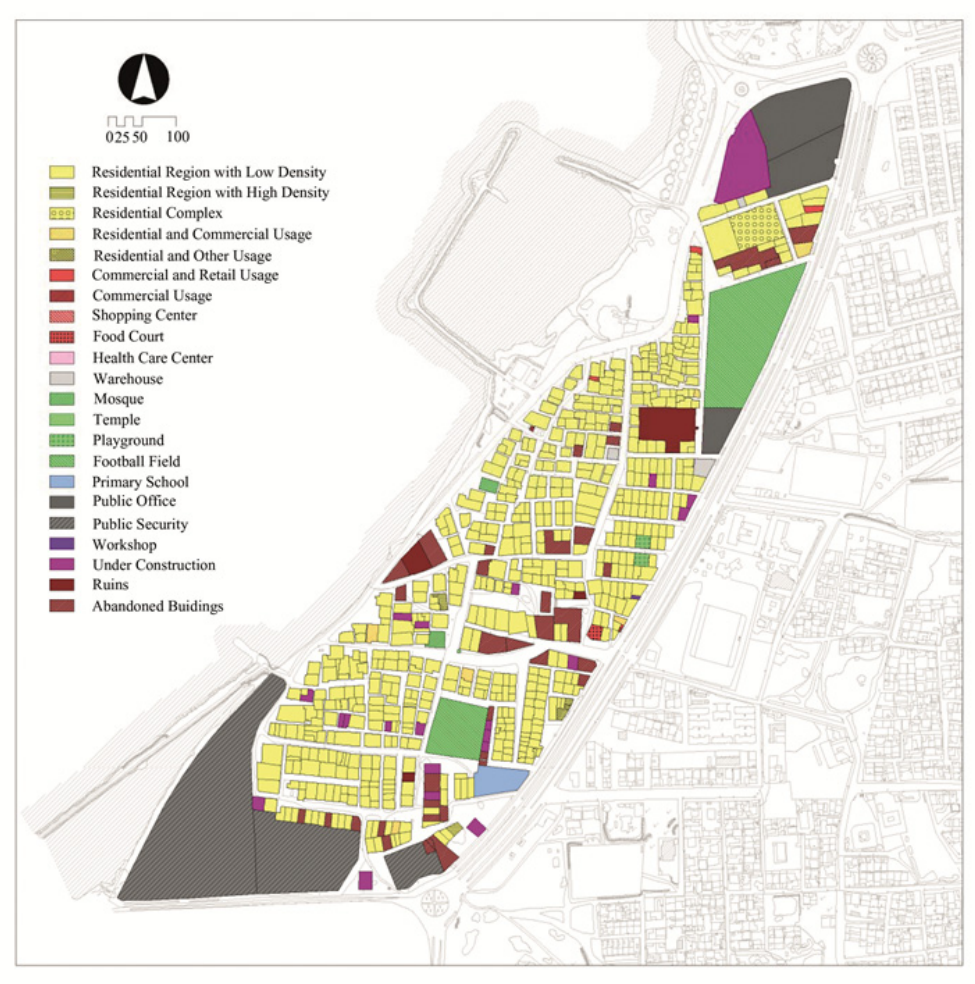

Figure 3. Usage Plan of Joffre (ibid)

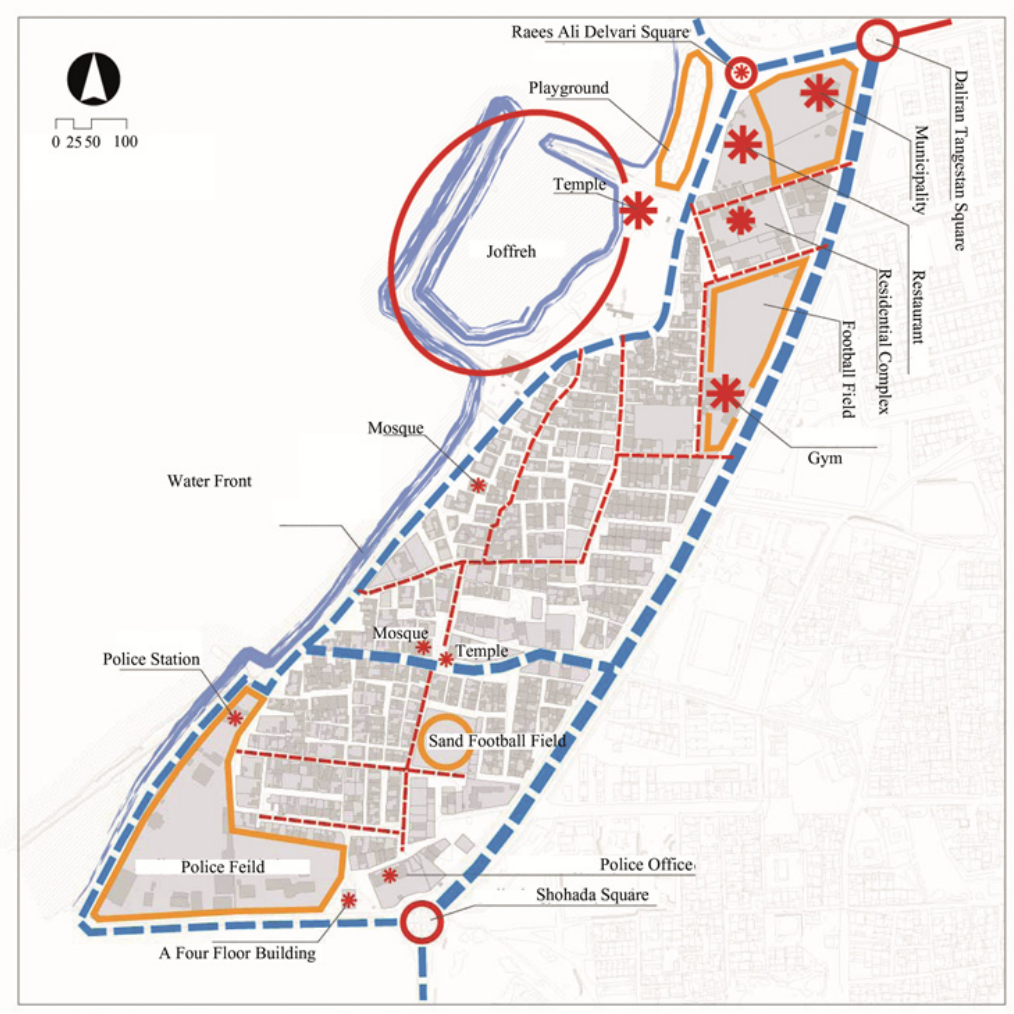

Figure 4. A physical plan of Joffre sector (ibid) 
Table 1. The effective factors in the coastal townscape in Joffre

\begin{tabular}{|c|c|c|c|c|}
\hline $\begin{array}{l}\text { Effective Factors } \\
\text { Joffre townscape }\end{array}$ & Strengths & Weaknesses & Opportunities & Threats \\
\hline Environment & $\begin{array}{l}\text { - Controlling Fishing } \\
\text { Activities Pollution } \\
\text {-Direct Access to Sea }\end{array}$ & $\begin{array}{l}\text { - Passages Flooded } \\
\text {-Accumulation of } \\
\text { Construction Waste } \\
\text {-Shortage of Vegetation in } \\
\text { all Region }\end{array}$ & $\begin{array}{l}\text { - in the Vicinity of the Sea } \\
\text {-Tourism Development }\end{array}$ & $\begin{array}{l}\text {-Process of Rebuilding } \\
\text { with nonrenewable } \\
\text { Materials } \\
\text {-Process of Rebuilding } \\
\text { based on Building Model } \\
\text { incompatible with Climate }\end{array}$ \\
\hline $\begin{array}{l}\text { Physical Form of } \\
\text { the City }\end{array}$ & $\begin{array}{l}\text {-Wide View to the Sea } \\
\text {-Location of the Fishing } \\
\text { Wharf } \\
\text { - Desirable Physical } \\
\text { Permeability }\end{array}$ & $\begin{array}{l}\text {-Very Low Quality of the } \\
\text { Building } \\
\text {-Discontinuity of Urban } \\
\text { Bodies } \\
\text {-Very Low Quality of the } \\
\text { Environment }\end{array}$ & $\begin{array}{l}\text { - Frequency of Arid Lands for } \\
\text { Rebuilding }\end{array}$ & $\begin{array}{l}\text { - Increasing Process of } \\
\text { Rebuilding without } \\
\text { Criterion }\end{array}$ \\
\hline $\begin{array}{l}\text { Movement and } \\
\text { Access }\end{array}$ & $\begin{array}{l}\text {-Suitability of Width } \\
\text { Passages based on Height } \\
\text { and volume of the } \\
\text { Buildings }\end{array}$ & $\begin{array}{l}\text { - Lake of Suitable Flooring } \\
\text { for Passengers } \\
\text { - Problem of Expulsion of } \\
\text { Surface Water during } \\
\text { Rainfall }\end{array}$ & & $\begin{array}{l}\text { Destroying high Levels of } \\
\text { Land based on Applying } \\
\text { Widening Passages }\end{array}$ \\
\hline Usage & $\begin{array}{l}\text {-the Existence of Sport } \\
\text { Usage in this Region } \\
\text {-Tendency and Continuing } \\
\text { the Process of Rebuilding } \\
\text { in this Region }\end{array}$ & $\begin{array}{l}\text { - Shortage of Education } \\
\text { Usage } \\
\text { - Shortage of } \\
\text { Cultural-Recreation Usage } \\
\text {-Shortage of } \\
\text { Health-Treatment Usage in } \\
\text { this Region }\end{array}$ & $\begin{array}{l}\text { - Possibility of Applying Joffre } \\
\text { Pond in Providing } \\
\text { Recreation-Leisure Usage }\end{array}$ & $\begin{array}{l}\text { - Existence of Around } \\
\text { Incompatible Usage }\end{array}$ \\
\hline
\end{tabular}

\section{Presenting Solution and Suggestion}

- Coordination in details, scale, proportionality of the texture, materials, color and form of buildings in the historical and old textures (protecting face bricks, pitched roof, old buildings) through urban plans especially for every passage or axis.

- Giving permit for views against the environment and street appearance should be prevented (controlling banks and views in the street view).

- Studying the appointed or suggested points as registered national monuments in the considered region and comments and recommendation for planning neighborhoods and city view of these points to provide the background for creating continuity in all historical textures (it means changing points to axis and spots in detailed plan scale).

- Making a powerful executive structure in municipality with determined duties for observing and controlling in performance of public and individual plans.

- $\quad$ Providing qualitative identifications for applicants for damaging and rebuilding buildings.

- $\quad$ Planting trees in the middle axis of the street for making shadow.

- Recognition the physical distance of privacy in historical buildings based on used materials, height, collective dimensions and natural condition of the environment and studying the geology.

- Constructing high buildings should be prevented that causes the disorder in the environment coordination and affects the existed view and landscape.

- $\quad$ Using uncoordinated and discordant material should be prevented near the building.

- Organizing and creating green space in the privacy of the buildings or considering technical and archeological criterion.

- Removing of historical supplements of the building and composed domains around it should be prevented

- Attempt to protect combination of composed piece of urban texture which is located near the historical texture (Mehdizadeh \& Masoomian, 2010, p. 96).

\section{References}

Bacon, E. (1976). Design of the Cities. New York: Penguin Books. 
Bell, S. (2003). Townscape: Pattern, Perception and Process. (Behnaz Aminzadeh). Tehran: Tehran University Publication.

Billings, K. (1993). Quality in Design. University of Sydney: Department of Architecture.

Cullen, G. (2003). Townscape Concise. (Manouchehr Tabibiyan). Tehran: Tehran University Publication.

Detailed Plan of Boushehr. (2006). Urban Planning Organization of Boushehr.

Esfandiyari, M. (1997). A Prospect on Nature in Urban Habitat. Tehran Municipality Journal, 60, 61-68. Tehrran.

Feyzi, M., et al. (2007). Human-environmental Approach in Architectural Plan of Townscape. Education and Technology Journal, 3, 122-131. Tehran.

Golkar, K. (2000). Constructive Components of Urban Planning Quality. Soffe Journal, 32, 38-65. Tehran.

Golkar, K. (2006). Townscape Concept. Abadi Journal, 53, 38-47. Tehran.

Kaplan, S., \& Kaplan, R. (1998). Human Escape: Environments for People. Washington DC: Island Press.

Lynch, K. A. (2006). Town View. (Manouchehr Mozayani). Tehran: Tehran University Publications.

Mehdizadeh, F., \& Masoomian, F. (2010). Necessity of Attitude toward Designing New Fabric Elevations Adjacent to Old Fabric in Historic Cities. Danesh Nama Journal, 180, 95-103. Tehran.

Pakzad, J. (2010). Theoretical Basis and Urban Planning Process. (4th Ed.). Tehran: Shahidi Publication.

Spirn, A. (1984). The Granite Garden: Urban Nature and Human Design. Basic Book.

Mansouri, S. A. (2010). Coast, Unknown Opportunities for Promoting Space Quality. Art and Architecture Journal, 9, 4-5. Tehran.

\section{Copyrights}

Copyright for this article is retained by the author(s), with first publication rights granted to the journal.

This is an open-access article distributed under the terms and conditions of the Creative Commons Attribution license (http://creativecommons.org/licenses/by/4.0/). 